\title{
Citizenship, Governance and Communication
}

\author{
Michael Williams
}

\begin{abstract}
Information and communication technologies (ICTs) are transforming the engagement of citizens in political life at local, regional, national and international levels. Citizenship can be framed in nationally bounded constitutional and legal terms. It can also be framed in a discourse that is not bounded by national boundaries; ICTs facilitate communication between persons and groups who share a common language and sets of concerns. Gender equality, terrorist activity and statelessness are three global issues that highlight changing citizenship issues in the global village and the information-rich global society.
\end{abstract}

Keywords Agency - Defining citizenship

\section{E-Citizenship and E-Governance}

In recent decades, for politicians in some advanced democracies participatory citizenship is associated less with communal action, seen in the supportive work of multiple charities, voluntary agencies and informal social groups, and more with political engagement, especially with voting behaviour. In some countries there has been a marked decline in voters exercising their hard earned right to vote in local, national, and in the European Union, international elections. ICTs are increasingly being seen as an essential way of bridging the divide between the governors and the governed. Of course, the potential value of ICTs in this role is seen differently from either side of the divide. Selected publications, one from Canada and the other from an international organization, illustrate this.

M. Williams $(\bowtie)$

Swansea University, Swansea, UK

e-mail: michaeltwilliams8@btinternet.com

(C) The Author(s) 2016

M.E. Robertson (ed.), Communicating, Networking: Interacting,

SpringerBriefs in Global Understanding, DOI 10.1007/978-3-319-45471-9_3 
- The Canadian publication (Peters and Abud 2009) explores the democratic deficit identified in three trends: declining voter turnout, falling rates of participation in political parties, and declining trust in political leadership. These trends are not unique to Canada. They had been highlighted earlier, for example, in a British government consultation paper (Office of the e-Envoy 2002). Peters and Abud seek a "new and meaningful form of democracy" (p. 8) in which citizens engage in "deliberation and informed participation" (p. 8). Through case studies they show how through e-consultation central government can engage in processes that are alternatives to simple top-down information delivery. Their focus is on civic literacy and the involvement of citizens via ICTs in processes that go beyond consultation to include deliberation and evaluation. While this might be seen as a challenge to governments to respond to rapid changes in the information society there are more profound challenges that accompany the availability of ICTs. On the one hand, technology itself lies in the hands of powerful multi-national corporations, who may or may not be subjected to national controls. On the other hand, messages carried by ICTs may come from anywhere on the globe, and censoring these by governments becomes increasingly difficult. The power of the message has been passing to the people and the power of the technology has passed to private corporations. Through this, the local becomes the global and the global becomes the local. This, of course has a flip side. ICTs carry not only positive messages. They carry propaganda and they have enormous potential for legal and illegal, public and clandestine, surveillance of persons and organizations as they go about their legitimate and illegitimate local, national and international everyday private and public lives.

- The second publication (Economic Commission for Africa 2008) focuses on Africa. While the Canadian discussion has special resonance in the advanced and wealthier nations of the First World, a different context is to be found in the less-advanced and impoverished countries of the Third World. Half a century ago the division between the First and Third Worlds was defined in terms of wealth: financial poverty bringing with it an array of problems, not least in nutrition, health, housing and education. To the infrastructural inadequacies of these countries must now be added the inaccessibility of ICTs. The verbs "Have" and "Have not" must be redefined to take this into account. The authors of an African report (Economic Commission for Africa 1996) warn of the widening gap between information rich and information poor countries with the danger of Africans becoming second class status in a new world order. The ambitious vision of the African Information Society Initiative was of Africa becoming by 2010 "an information society in which every man, woman, child, village, public and private sector office has secure access to knowledge through the use of computers and communication media" (Economic Commission for Africa 2008, p. 8). 


\section{Looking Back}

The opening sentences in the Publisher's Note to the Pelican version (1944) of Mackinder's Democratic Ideals and Reality: A Study in the Politics of Reconstruction read, "In the 20th century we must see things in the big. Statesmen must think in continents, industrialists in world markets". At that time many citizens were either fighting in World War II or seeking simply to survive, often in the most dangerous and difficult of circumstances. Citizens were thinking small, concerned about themselves, their families and their local communities. In the twenty-first century, it could be argued, superficially little appears to have changed, apart from the increasing use of the word globalisation to embrace a wide range of phenomena that are rapidly changing with the introduction of more and more sophisticated information and communication technologies (ICTs). More profoundly, the relationships between individuals and governments, at all levels, have changed and are changing, partly as a response to the dissemination of ICTs. An examination of the concept of citizenship helps to clarify this.

\section{Citizenship Defined}

Injecting the word citizenship into any discussion may be compared to throwing a pebble into a pond and watching the ripples spread from the point of impact to the periphery. The ripples reduce in intensity with distance as they enlarge and spread. Citizenship needs to be spatially contextualised, not least because it is most commonly defined in nationally-specific legal terms: citizenship is integral to statehood and nationality, both spatially bounded. But citizenship can be defined in terms other than those associated with national identity and legally defined rights, duties, and obligations. Citizenship "can also be applied in a wider sense, to the way an individual perceives and practises being a human being in a society, and/or as a member of an interest group, according to his or her own perception of what is right. That is, on the basis of moral judgement" (Williams and Humphrys 2003, p. 4). Beneath this simple distinction, the constitutional and the communal, lies much complexity.

The turmoil in the Middle East, focused on the troubles of Iraq and Syria, exemplifies the difficulties surrounding the definition of national boundaries. The societal pluralism found in metropolitan cities worldwide exemplifies the problems of defining society. For the latter, it can be argued, that the multiplicity of social groups within a specific place yields multiple definitions of citizenship. Thus, citizenship is perceived differently by persons according to, among others, their age, gender, class, religion, race, language, ethnicity, physical and mental ability and location. Just to complicate things further, there is increasing attention being paid to such concepts as world citizenship, transnational citizenship, dual nationality, environmental citizenship and, even, academic citizenship. Some of these can be 
seen clearly in current crises in Europe, not least in Ukraine, but also in the migration of European citizens within Europe and non-Europeans trying to cross the Mediterranean and the Channel. For ordinary citizens in a stable political culture, none of these issues occupy much of their time and thinking. By contrast, in places of economic hardship, day to day survival is all consuming. Obtaining clean drinking water and an adequate supply of food and firewood is the constant preoccupation of many people, especially in Sub-Saharan Africa. The precariousness of life for persons in places threatened by such natural hazards as severe droughts, riverine flooding, tsunamis, earthquakes and volcanic activity as well as the exigencies of civil strife and war, also overwhelms any concerns with citizenship. The responses to such human disasters by local communities demonstrate citizenship in action. Such active citizenship is often seen to be more effective in the short run than any governmental efforts. All of this is some distance from political discussions about participatory citizenship.

\section{Particular Issues}

\section{Terrorism}

International terrorism has become one of the most serious, if not the most serious of global problems. The ability of terrorist groups to utilise ICTs for propaganda purposes, for planning and implementing activities worldwide and to recruit newcomers to their cause has challenged governments to devise counter-measures that also employ ICTs. Electronic surveillance is part of this, though its use is contentious since the methods employed can be seen as intrusions into private life and there is much scope for misuse. In some countries there is an ongoing debate about the need to censor the internet in an attempt to curb the flow of information that might benefit terrorist groups and this too is contentious.

\section{Gender}

Gender equality is one of the Millennium Goals identified by the United Nations for a programme that started in 2000 with completion in 2015. The goal was to promote gender equality and empower women. High on the list of issues prioritised by the UN are the ending of violence and harassment towards women, the equalising of educational opportunities, especially in primary schools, greater participation in political institutions and more involvement of women in political life. The plight of women and how this is handled in the media is exemplified by the attack on Malala Yousafzai in Pakistan in 2012 and the abduction in 2014 by gunmen of more than two hundred and fifty schoolgirls from a Government Secondary School in Nigeria. 
In the context of citizenship and governance, at an international institutional level the gender equality agenda is framed by improving the presence of women. At street, village and community level the agenda is framed by finding ways for women's voices to be heard. As a UN Women report asserts that, for gender relations to be transformed, women and girls ... "should see the expansion of the full range of human capabilities and have access to a wide range of resources on the same basis as men and boys, and they should have a real presence and voice in the full range of institutional fora ..." (UN Women 2013, pp. 3-4). For women who own and control mobile phones and computers, their world has been transformed. Provided the technological infrastructure is in place and costs are not prohibitive, they have been empowered to engage in social, cultural and political communication that can lead to various forms of engagement, especially political engagement. They can seek to effect policy changes at local and national levels through formal consultation processes and direct action. Using social media they can engage in international communication, provided that there is a shared language between the correspondents. This is not to suggest that opportunities are equal even within national boundaries. Networking is much easier and quicker in cities than in rural areas, not least because ICTs are more accessible there.

\section{Statelessness and Migration}

Statelessness is a contemporary phenomenon that has several facets. For example, there is the statelessness of elite jetsetters, corporate businessmen and women who migrate from home to home and company to company in locations scattered worldwide. They are in the same category as high value sportsmen and sportswomen, and others from the entertainment communities who appear to flit with ease from one continent to another. By contrast, there are the refugees, asylum seekers and migrants whose intracontinental and intercontinental travelling is anything but easy. Regarding the latter, the United Nations High Commission for Refugees estimated that in 2014 some 59.5 million people were forcibly displaced. Of these, 19.5 million were refugees, 38.2 million were internally displaced and 1.8 million were asylum seekers (UNHCR 2015). To bring some scale to these enormous figures, it was estimated that 42,500 people were forced to migrate per day as a result of civil conflict and persecution. ICTs have converted the statistics into personal stories, bringing a sense of immediacy to the forces that have driven people to migrate on hazardous journeys sometimes across oceans and sometimes overland. The mass media project images in real time of scenes from the Mediterranean, the Pacific and the US-Mexican border. They also display similar images from pressure points in Africa and Asia. It is important to recognise that Turkey received most refugees in 2014 (1.59 million), followed by Pakistan, Lebanon, Iran, Ethiopia and Jordan. In Sub-Saharan Africa, Africa's numerous conflicts, including in Central African Republic, South Sudan, Somalia, Nigeria, Democratic Republic of Congo, together produced immense forced displacement 
totals in 2014, on a scale only marginally lower than in the Middle East. The political consequences of these migrants are immense for the migrants themselves, especially for those who end up in vast camps, as well as for the governments that have to cope with the arrivals when their own resources are inadequate. Integral to the everyday life of the displaced and stateless is the loss of any rights to education, health care, housing and other aspects of life taken for granted in more advantaged communities.

\section{Conclusions}

In the context of citizenship and governance, there is an abundance of international documents produced by agencies such as the United Nations, the World Bank and the OECD that have produced discussion papers, organised conferences and published discussion papers, expert reports and published recommendations, roadmaps and sets of goals for national governments to consider. In parallel, national and local governments have addressed these issues for their citizens. Meanwhile, non-governmental organizations, operating at a variety of scales and scholars from a range of academic disciplines have set their own agendas for study, research and communal activity. There are many voices to be heard and ICTs have provided the means for individuals to contribute at many levels. Voices may or may not have power and authority. Their capacity to influence governmental policies and practices will vary according to local and national circumstances. One needs only to consider the resources and opportunities available in contrasting environments such as the megacities of the First World and the scattered rural villages of the Third World. Increasingly, ICTs are creating new inter-linked communities varying from the local to the global. They challenge our conventional understanding of citizenship and pose problems for governments seeking to function efficiently, transparently and accountably.

Open Access This chapter is distributed under the terms of the Creative Commons Attribution 4.0 International License (http://creativecommons.org/licenses/by/4.0/), which permits use, duplication, adaptation, distribution and reproduction in any medium or format, as long as you give appropriate credit to the original author(s) and the source, provide a link to the Creative Commons license and indicate if changes were made.

The images or other third party material in this chapter are included in the work's Creative Commons license, unless indicated otherwise in the credit line; if such material is not included in the work's Creative Commons license and the respective action is not permitted by statutory regulation, users will need to obtain permission from the license holder to duplicate, adapt or reproduce the material. 


\section{References}

Office of the e-Envoy, Cabinet Office 2002. In the Service of Democracy: a consultation paper on a policy for electronic democracy. London: HM Government.

Peters, J. and Abud, M. 2009. E-Consultation: enabling democracy between elections. IRPP (Institute for Research on Public Policy) Choices, 15(1): 2-31.

UN Economic Commission for Africa 1996. African Information Society Initiative: An action framework to build Africa's information and communication infrastructure. Addis Ababa: UN Economic Commission for Africa.

UN Economic Commission for Africa 2008. African Information Society Initiative (AISI): A decade's perspective. Addis Ababa: UN Economic Commission for Africa.

UNHCR 2015. Global Trends Report: World at War: Forced Displacement in 2014. Geneva: UNHCR

UN Women 2013. A Transformative Stand-Alone Goal on Achieving Gender Equality, Women's Rights and Women's Empowerment: Imperatives and Key Components. New York: UN Women.

Williams, M. and Humphrys G. eds., 2003.Citizenship Education and Lifelong Learning: Power and Place. New York: Nova Science Publishers Inc. 